Tropical Journal of Pharmaceutical Research February 2015; 14 (2): 293-301

ISSN: $1596-5996$ (print); 1596-9827 (electronic) (C) Pharmacotherapy Group, Faculty of Pharmacy, University of Benin, Benin City, 300001 Nigeria.

All rights reserved.

Available online at http://www.tjpr.org

Original Research Article

http://dx.doi.org/10.4314/tjpr.v14i2.15

\title{
Perceptions, Experiences and Expectations of Physicians Regarding the Role of the Pharmacist in an Iraqi Hospital Setting
}

\author{
Salim A Hamadi ${ }^{1 *}$, Mohammed M Mohammed ${ }^{2}$, Kawa A Dizaye ${ }^{3}$ and Iman A \\ Basheti ${ }^{4}$ \\ ${ }^{1}$ Department of Pharmacology and Basic Biomedical Sciences, Faculty of Pharmacy, Petra University, Amman, Jordan, ${ }^{2}$ \\ Department of Clinical Pharmacy, College of Pharmacy, Al-Mustansiriya University, Baghdad, Iraq, ${ }^{3}$ Pharmacology Department, \\ College of Medicine, Hawler Medical University, Erbil, Iraq, ${ }^{4}$ Department of Clinical Pharmacy and Therapeutics, Faculty of \\ Pharmacy, Applied Science University, Amman, Jordan
}

*For correspondence: Email: shamadi@uop.edu.jo; Tel: +962 796841854

Received: 4 July 2014

Revised accepted: 8 January 2015

\begin{abstract}
Purpose: To investigate the perceptions, expectations, and experiences of physicians regarding hospital-based pharmacists in some Iraqi government hospitals.

Methods: A cross-sectional study was conducted at four government hospitals in Baghdad and Erbil, Iraq from March to July 2012. A validated, self-administered questionnaire was hand-delivered to a random sample of 200 physicians. The questionnaire comprised four sections that probed the physicians' demographic characteristics as well as their perceptions of, expectations of, and experiences with hospital pharmacists.

Results: Most participants (69.4\%) reported rarely interacting with pharmacists and that enquiring about the availability of medications was the main purpose $(74.9 \%)$ of any interactions. Physicians reported being comfortable with pharmacists preventing prescription error, treating minor illness, and suggesting prescription medication to physicians of 74,75 and $67 \%$, respectively, but only $47 \%$ were comfortable with pharmacists providing patient education. The perspective of physicians in Erbil differed from that of physicians in Baghdad ( $p<0.05)$.

Conclusion: Interactions between Iraqi physicians and pharmacists are still not optimal. Physicians are much more comfortable with traditional pharmacist functions than with the extended, patient-oriented pharmacy services currently being promoted. Great efforts are needed to enhance the Iraqi physician's attitude regarding the clinical services provided by pharmacists which in turn would result in more collaboration among healthcare professionals.
\end{abstract}

Keywords: Physician, Pharmacist, Perception, Experience, Expectation, Patient-oriented, Pharmacy service

Tropical Journal of Pharmaceutical Research is indexed by Science Citation Index (SciSearch), Scopus, International Pharmaceutical Abstract, Chemical Abstracts, Embase, Index Copernicus, EBSCO, African Index Medicus, JournalSeek, Journal Citation Reports/Science Edition, Directory of Open Access Journals (DOAJ), African Journal Online, Bioline International, Open-J-Gate and Pharmacy Abstracts

\section{INTRODUCTION}

The traditional relationship between the physician as a prescriber and the pharmacist as a dispenser can no longer suffice to ensure the safety effectiveness and adherence to therapy.
Pharmacists must pay more attention to patientcentered, outcome-focused care to optimize the safe and effective use of drugs.

Pharmacy as a profession has changed from the traditional role in a product-oriented pharmacy to 
a more clinical role in the patient-oriented pharmacy with outcome-focused care that involves pharmaceuticals [1,2]. The roles of pharmacists are developing rapidly to keep pace with the needs of an advanced healthcare system. Pharmacists recognize the need to promote the safe use of medicines and are willing to accept this responsibility to ensure maximum therapeutic benefit [3].

Physicians and pharmacists in the developed world enjoy a good professional relationship, resulting in safer, more effective, and less costly drug therapy [4]. Many studies report that physicians are receptive to several clinical services provided by the pharmacist [5-7]. However, communication gaps between pharmacists and doctors have been also reported [8-10]. The pharmacy profession in developing countries continues to face many barriers, including an acute shortage of qualified pharmacists and a lack of standard practice guidelines [11].

Studies have been conducted in some Arab countries to evaluate physicians' perceptions and expectations of the role of hospital pharmacists. The results varied from physicians being comfortable with pharmacists providing a broad range of services $[12,13]$ to being uncomfortable even in the case of suggestions for minor illnesses $[14,15]$. The aim of this study was to evaluate physicians' perceptions expectations and experiences with pharmacists' professional services in Iraqi government hospitals.

\section{METHODS}

\section{Subject and design}

The study was a cross-sectional study, conducted in four government hospitals in Baghdad, and Erbil, both in Iraq. The study was performed for five months (March to July 2012). The participants were randomly selected from lists provided by their facility administrators. A validated questionnaire was hand-delivered to the random sample of 200 physicians. A trained research assistant explained the study aims and the various parts of the questionnaire to the physicians. Data collection was conducted by a single trained research assistant to ensure consistency.

The questionnaire used in this investigation was adapted with minor modifications from previously published studies [12-15]. The questionnaire was composed of four sections: Section 1(A) requested demographic information such as age, gender, place of work, current position and area of specialization, qualification year, and country of graduation. Section $1(B)$ investigated the physician's interactions with pharmacists (frequency and purposes), perceptions of the pharmacy profession, and whether the physician perceived pharmacists as healthcare professionals. Section 2 included eight questions to investigate the physician's level of comfort with pharmacists performing 'pharmaceutical care' duties. Section 3 included eight questions to explore the physician's expectations of pharmacists, whereas Section 4 included eight questions that measured the actual experiences of the physician with pharmacists.

\section{Data analysis}

Participants' responses were encoded, and the data analyzed using Statistical Package for the Social Sciences (SPSS, version 14, Chicago, IL, US). Descriptive analyses were performed to determine the proportion of physicians who selected each of the options for the different parts of the questionnaire. A Chi square test was used to identify any significant difference among the participants' responses, with significance defined as a $p$-value $\leq 0.05$.

\section{RESULTS}

A total of 194 physicians were recruited into the study. A significant difference in the age of participants ( $p<0.001$, chi square test) between Baghdad and Erbil was found, with a lower mean age amongst the physicians recruited in Baghdad (Table 1). The gender distribution also differed significantly between the two groups $(p<$ 0.001 , chi square test) with more males recruited in Baghdad (100 \%) than in Erbil (50.5\%).

No significant difference $(p=0.141)$ was found concerning the country in which the physician qualified between the two groups; $94.7 \%$ of the combined group obtained their qualification in Iraq. Most participants (46.4\%) obtained their degree between 1991 and 2000, while a significantly higher proportion of participants $(p<$ 0.001 ) from Erbil obtained their degree after the year $2000(58.0 \%$ in Erbil vs. $19.2 \%$ in Baghdad).

All the specialists from Erbil were working in general hospitals, while most specialists in Baghdad were working in specialized hospitals (Table 1). Significantly more physicians from Baghdad were juniors compared to the Erbil group ( $p<0.001)$, and more Baghdad physicians specialized in general medicine $(p=0.049)$ than 
did Erbil physicians, the majority of whom specialized in surgery (Table 1).

\section{Current physicians' interactions with pharmacists}

Most physician participants $(69.4 \%)$ reported rarely interacting with pharmacists. Approximately $26 \%$ interacted with pharmacists weekly; only $4.7 \%$ interacted with pharmacists daily, with significant differences in the levels of interaction found between the groups in each city $(p<0.001)$.

The purposes of physician-pharmacist interactions were highly varied; inquiries into the availability of medications constituted most interactions $(74.9 \%)$. Other interactions involved discussions of side effects, drug alternatives, drug dosages, and drug interactions, with significant differences in the distribution detected between the groups in each city $(p<0.001)$ (Table 2).

Table 1: Physicians' demographics ( $N=194)$
While most participants (89.2 \%) considered pharmacists healthcare professionals, most also believed that the pharmacy is a business.

\section{Level of physician comfort with performance of specific duties by pharmacists}

Only $47.9 \%$ of the participants were comfortable or moderately comfortable with pharmacists providing patient education, with a significantly higher proportion from Erbil answering "Comfortable" or "Moderately comfortable" than from Bagdad (Table 3). Approximately half the respondents $(44.9 \%)$ were comfortable or moderately comfortable with pharmacists suggesting the use of non-prescription medications, and $44.2 \%$ and $77.2 \%$ of the participants were comfortable or moderately comfortable, respectively, with a pharmacist suggesting the use of prescription medications to patients and physicians (Table 3 ).

Most participants $(79.9 \%)$ were comfortable or moderately comfortable with pharmacists treating minor illnesses. A significantly higher proportion

\begin{tabular}{|c|c|c|c|c|}
\hline Variable & $\begin{array}{l}\text { Baghdad } \\
\text { N (\%) }\end{array}$ & $\begin{array}{l}\text { Erbil } \\
\text { N (\%) }\end{array}$ & $\begin{array}{l}\text { Total } \\
\text { N (\%) }\end{array}$ & $P$-value \\
\hline \multicolumn{5}{|l|}{ Age (years) } \\
\hline$\leq 35$ & $51(54.3)$ & $23(24.2)$ & 74 (39.2) & \multirow{3}{*}{$<0.001$} \\
\hline $36-50$ & $24(25.5)$ & 56 (58.9) & $80(42.3)$ & \\
\hline$\geq 51$ & 19 (20.2) & $16(16.9)$ & 35 (18.5) & \\
\hline \multicolumn{5}{|l|}{ Gender } \\
\hline Male & $94(100.0)$ & $50(50.5)$ & $144(74.6)$ & \multirow{2}{*}{$<0.001$} \\
\hline Female & $0(0.0)$ & $49(49.5)$ & $49(25.4)$ & \\
\hline \multicolumn{5}{|c|}{$\begin{array}{l}\text { Country in which } \\
\text { qualification was obtained }\end{array}$} \\
\hline USA & $2(2.1)$ & $0(0.0)$ & $2(1.0)$ & \multirow{4}{*}{0.141} \\
\hline Europe & $1(1.1)$ & $0(0.0)$ & $1(0.5)$ & \\
\hline Iraq & 89 (94.7) & $100(0.0)$ & $189(97.5)$ & \\
\hline Other & $2(2.1)$ & $0(0.0)$ & $2(1.0)$ & \\
\hline \multicolumn{5}{|l|}{ Place of work } \\
\hline Specialized hospital & $70(74.5)$ & $0(0.0)$ & $70(36.1)$ & \multirow{3}{*}{$<0.001$} \\
\hline General hospital & $24(25.5)$ & $100(100.0)$ & $124(63.9)$ & \\
\hline \multicolumn{4}{|l|}{ Current position } & \\
\hline Junior Registrar & $40(42.6)$ & $11(11.0)$ & $51(26.3)$ & \multirow{4}{*}{$<0.001$} \\
\hline Senior Registrar & $49(52.1)$ & $30(30.0)$ & $79(40.7)$ & \\
\hline Consultant & $5(5.3)$ & $53(53.0)$ & $58(29.9)$ & \\
\hline Other & $0(0.0)$ & $6(6.0)$ & $6(3.1)$ & \\
\hline \multicolumn{5}{|l|}{ Specialization } \\
\hline Medicine & $38(40.4)$ & $27(27.0)$ & $65(33.5)$ & \multirow{4}{*}{0.049} \\
\hline Surgery & $43(45.8)$ & $52(52.0)$ & $95(49.0)$ & \\
\hline Pediatrics & $0(0.0)$ & $5(5.0)$ & $5(2.6)$ & \\
\hline Others & $13(13.8)$ & $16(16.0)$ & $29(14.9)$ & \\
\hline \multicolumn{5}{|l|}{ Year of qualification } \\
\hline Before 1981 & $3(3.2)$ & $1(1.0)$ & $4(2.0)$ & \multirow{4}{*}{$<0.001$} \\
\hline $1981-1990$ & $18(19.15)$ & $6(6.0)$ & $24(12.4)$ & \\
\hline $1991-2000$ & $55(58.5)$ & $35(35.0)$ & $90(46.4)$ & \\
\hline After 2000 & $18(19.15)$ & $58(58.0)$ & $76(39.2)$ & \\
\hline
\end{tabular}


Table 2: Physician interactions with pharmacists $(\mathrm{N}=194)$

\begin{tabular}{|c|c|c|c|c|}
\hline Variable & $\begin{array}{c}\text { Baghdad } \\
\mathbf{N}(\%)\end{array}$ & $\begin{array}{l}\text { Erbil } \\
\text { N (\%) }\end{array}$ & $\begin{array}{l}\text { Total } \\
\text { N (\%) }\end{array}$ & $P$-value \\
\hline \multicolumn{5}{|l|}{ Frequency of interaction } \\
\hline Never/ Rarely & $86(91.5)$ & 48 (48.5) & $134(69.4)$ & \multirow{3}{*}{$<0.001$} \\
\hline Weekly & $8(8.5)$ & $42(42.4)$ & $50(25.9)$ & \\
\hline Daily & $0(0.0)$ & $9(9.1)$ & $9(4.7)$ & \\
\hline \multicolumn{5}{|l|}{ Purpose of interaction } \\
\hline Drug availability & $90(95.7)$ & $53(54.6)$ & $143(74.9)$ & \multirow{7}{*}{$<0.001$} \\
\hline Side effects & $0(0.0)$ & $17(17.6)$ & $17(8.9)$ & \\
\hline Drug alternatives & $0(0.0)$ & $11(11.3)$ & $11(5.7)$ & \\
\hline Drug dosage & $0(0.0)$ & $7(7.2)$ & $7(3.7)$ & \\
\hline Drug interactions & $0(0.0)$ & $2(2.1)$ & $2(1.0)$ & \\
\hline Drug availability \& Side effects & $4(4.3)$ & $0(0.0)$ & $4(2.1)$ & \\
\hline Others & $0(0.0)$ & $7(7.2)$ & $7(3.7)$ & \\
\hline \multicolumn{5}{|c|}{ What do you think about pharmacy as a job? } \\
\hline Business & 83 (88.3) & $83(83.0)$ & $166(85.6)$ & \multirow{3}{*}{$<0.001$} \\
\hline Professional & $1(1.1)$ & $12(12.0)$ & $13(6.7)$ & \\
\hline Both (Business and Professional) & $10(10.6)$ & $5(5.0)$ & $15(7.7)$ & \\
\hline \multicolumn{5}{|c|}{ Is the pharmacist a health care professional (HCP)? } \\
\hline Yes & $94(100.0)$ & $79(79.0)$ & $173(89.2)$ & \multirow{2}{*}{$<0.001$} \\
\hline No & $0(0.0)$ & $21(21.0)$ & $21(10.8)$ & \\
\hline
\end{tabular}

Table 3: Physician comfort levels with performance of specific duties by pharmacists $(\mathrm{N}=194)$

\begin{tabular}{|c|c|c|c|c|c|}
\hline $\begin{array}{l}\text { Item } \\
\text { no. }^{a}\end{array}$ & Response & $\begin{array}{c}\text { Baghdad } \\
\text { N (\%) }\end{array}$ & $\begin{array}{c}\text { Erbil } \\
\mathbf{N}(\%) \\
\end{array}$ & $\begin{array}{c}\text { Total } \\
\mathbf{N}(\%) \\
\end{array}$ & $P$ P-value \\
\hline \multirow[t]{4}{*}{1} & Uncomfortable & 77 (81.9) & $18(18.4)$ & $95(49.5)$ & $<0.001$ \\
\hline & Moderately comfortable & $12(12.8)$ & 46 (46.9) & $58(30.2)$ & \\
\hline & Comfortable & $5(5.3)$ & 29 (29.6) & $34(17.7)$ & \\
\hline & No response & $0(0.0)$ & $5(5.1)$ & $5(2.6)$ & \\
\hline \multirow[t]{4}{*}{2} & Uncomfortable & $87(92.6)$ & $11(11.0)$ & $98(50.5)$ & $<0.001$ \\
\hline & Moderately comfortable & $6(6.4)$ & 61 (61.0) & $67(34.5)$ & \\
\hline & Comfortable & $1(1.0)$ & $21(21.0)$ & $22(11.4)$ & \\
\hline & No response & $0(0.0)$ & $7(7.0)$ & $7(3.6)$ & \\
\hline \multirow[t]{4}{*}{3} & Uncomfortable & 92 (97.9) & $12(12.2)$ & $104(54.2)$ & $<0.001$ \\
\hline & Moderately comfortable & $2(2.1)$ & 57 (58.2) & $59(30.7)$ & \\
\hline & Comfortable & $0(0.0)$ & 26 (26.5) & $26(13.5)$ & \\
\hline & No response & $0(0.0)$ & $3(3.1)$ & $3(1.6)$ & \\
\hline \multirow[t]{4}{*}{4} & Uncomfortable & 30 (31.9) & $11(11.1)$ & $41(21.2)$ & $<0.001$ \\
\hline & Moderately comfortable & $62(66.0)$ & $54(54.6)$ & $116(60.1)$ & \\
\hline & Comfortable & $2(2.1)$ & $31(31.3)$ & $33(17.1)$ & \\
\hline & No response & $0(0.0)$ & $3(3.0)$ & $3(1.6)$ & \\
\hline \multirow[t]{4}{*}{5} & Uncomfortable & $14(14.9)$ & $17(17.0)$ & $31(16.0)$ & \\
\hline & Moderately comfortable & 69 (73.4) & $51(51.0)$ & $120(61.9)$ & 0.002 \\
\hline & Comfortable & $11(11.7)$ & $26(26.0)$ & $37(19.0)$ & \\
\hline & No response & $0(0.0)$ & $6(6.0)$ & $6(3.1)$ & \\
\hline \multirow[t]{4}{*}{6} & Uncomfortable & $36(38.3)$ & $8(8.1)$ & $44(22.8)$ & $<0.001$ \\
\hline & Moderately comfortable & $50(53.2)$ & $34(34.3)$ & $84(43.5)$ & \\
\hline & Comfortable & $8(8.5)$ & $51(51.5)$ & $59(30.6)$ & \\
\hline & No response & $0(0.0)$ & $6(6.1)$ & $6(3.1)$ & \\
\hline \multirow[t]{4}{*}{7} & Uncomfortable & $68(72.4)$ & $15(15.0)$ & $83(42.8)$ & $<0.001$ \\
\hline & Moderately comfortable & $24(25.5)$ & 37 (37.0) & $61(31.4)$ & \\
\hline & Comfortable & $2(2.1)$ & $43(43.0)$ & $45(23.2)$ & \\
\hline & No response & $0(0.0)$ & $5(5.0)$ & $5(2.6)$ & \\
\hline \multirow[t]{4}{*}{8} & Uncomfortable & $76(80.9)$ & $20(20.0)$ & $96(49.5)$ & $<0.001$ \\
\hline & Moderately comfortable & $18(19.1)$ & 32 (32.0) & $50(25.8)$ & \\
\hline & Comfortable & $0(0.0)$ & 33 (33.0) & $33(17.0)$ & \\
\hline & No response & $0(0.0)$ & $15(15.0)$ & $15(7.7)$ & \\
\hline
\end{tabular}

a Item key: 1 = Providing patient education; 2 = Suggesting use of nonprescription medications; 3 = Suggesting use of specific prescription medications to patients; 4 = Suggesting use of prescription medication to physician; 5 = Treating minor illnesses; $6=$ Deleting and preventing prescription errors; $7=$ Designing and monitoring pharmacotherapeutic regimens; $8=$ Monitoring outcomes of pharmacotherapeutic regimens and plans 
of participants from Erbil compared to Baghdad $54.6 \%$ and $42.8 \%$ were comfortable or moderately comfortable regarding pharmacist's role in designing and monitoring pharmacotherapeutic regimens and in monitoring the outcomes of such regimens respectively. The majority $(74.1 \%)$ was comfortable or moderately comfortable with pharmacists making prescription deletions to prevent prescription errors.

\section{Physician expectations of pharmacists}

Approximately $46 \%$ of the participants agreed or strongly agreed that pharmacists should take personal responsibility for resolving any drugrelated problems they encounter. Only $39.7 \%$ of the participants agreed or strongly agreed that pharmacists are the drug experts. Most participants $(56.1 \%)$ agreed or strongly agreed that pharmacists could be depended upon to educate their patients about the safe and appropriate use of medication. Surprisingly, only $22.6 \%$ of the participants agreed or strongly agreed that they expect pharmacists to know the specific indication of each drug prescribed. A small proportion of participants (19.2\%) agreed or strongly agreed that they expect pharmacists to be available for consultation when physicians see patients during rounds; a significantly higher proportion of Erbil physicians than Baghdad physicians responded in this way (Table 4).

Approximately $53 \%$ of the participants agreed or strongly agreed that they expect pharmacists to assist them in designing drug therapy treatment plans for their patients. Approximately $42 \%$ agreed or strongly agreed that they expect pharmacists to assist in selecting appropriate non-prescription medications, with significant differences detected in the responses to these questions between physicians in the two cities (Table 4).

\section{Physician experiences with pharmacists}

Most physicians agreed or strongly agreed that pharmacists are a reliable source of general drug information (55.2\%) and of clinical drug information (57.7\%). Most participants $(56.2 \%)$ agreed or strongly agreed that pharmacists routinely counsel their patients on the safe and appropriate use of medications. Pharmacists were perceived as willing to take personal responsibility for resolving any drug-related problems they discover.
Of the physicians surveyed, $46.8 \%$ agreed or strongly agreed that pharmacists routinely inform them if the pharmacists discover clinical problems with their prescriptions, and $54.9 \%$ agreed or strongly agreed that pharmacists frequently inform them about more cost-effective alternatives to the drugs prescribed. Most participants $(60.4 \%)$ agreed or strongly agreed that pharmacists frequently ask them to clarify the drug therapy objectives the physician has in mind for their patients. Most $(58.3 \%)$ agreed or strongly agreed that pharmacists frequently let the physician know that their patients have experienced some problem with medications. Table 5 shows significant differences between the responses from physicians in the two geographical areas.

\section{DISCUSSION}

Today, the extended duties and responsibilities of pharmacists in many practice settings have been well defined and documented. Among these duties are drug monitoring, patient education, provision of medication information, optimization of patient-specific drug regimens, reduction in medication errors and harmful drug interactions, and increased patient compliance as well as many other duties $[16,17]$. The future of the hospital pharmacist's role in healthcare depends on the willingness and initiative of pharmacists to become more active member of the healthcare team as well as on the perception of and acceptance by physicians of the new patient-oriented roles of pharmacists.

This is the first study to report important findings that explored the physician-pharmacist relationship in Iraq. Most physicians in Iraq consider pharmacists a member of the healthcare team, which is a similar finding to that reported in a study [17]. The frequency of interactions between physicians and pharmacists were low in Iraq and mainly related to drug availability, which was also consistent with another study [12]. The findings of the current study indicate that a lack of communication between physicians and pharmacists in Iraqi hospitals remains, and the pharmacist is still viewed by the physician merely as a dispenser of medicines.

In this study, Iraqi physicians' acceptance of pharmacists performing specific duties varied significantly with the locations of the physicians $(p<0.05)$. Most Iraqi physicians were comfortable or moderately comfortable with pharmacists deleting prescriptions to prevent 
Table 4: Physician expectations of pharmacists $(\mathrm{N}=194)$

\begin{tabular}{|c|c|c|c|c|c|}
\hline $\begin{array}{l}\text { Physician } \\
\text { expectation }^{a}\end{array}$ & Response & $\begin{array}{c}\text { Baghdad } \\
\text { N (\%) }\end{array}$ & $\begin{array}{c}\text { Erbil } \\
\text { N (\%) }\end{array}$ & $\begin{array}{c}\text { Total } \\
\text { N (\%) }\end{array}$ & $P$-value \\
\hline \multirow[t]{3}{*}{1} & Strongly disagree/Disagree & $9(9.6)$ & $36(36.0)$ & $45(23.2)$ & $<0.001$ \\
\hline & Neutral & $24(25.5)$ & $36(36.0)$ & $60(30.9)$ & \\
\hline & Agree/Strongly agree & $61(64.8)$ & $28(28.0)$ & $89(45.9)$ & \\
\hline \multirow[t]{3}{*}{2} & Strongly disagree/Disagree & $0(0.0)$ & $34(34.0)$ & $34(17.5)$ & $<0.001$ \\
\hline & Neutral & $44(46.8)$ & $39(39.0)$ & $83(42.8)$ & \\
\hline & Agree/Strongly agree & $50(53.2)$ & $27(27.0)$ & 77 (39.7) & \\
\hline \multirow[t]{3}{*}{3} & Strongly disagree/Disagree & $0(0.0)$ & $34(34.0)$ & $34(17.5)$ & $<0.001$ \\
\hline & Neutral & $20(21.3)$ & $37(37.0)$ & $57(29.4)$ & \\
\hline & Agree/Strongly agree & $74(78.7)$ & $29(29.0)$ & $103(53.1)$ & \\
\hline \multirow[t]{3}{*}{4} & Strongly disagree/Disagree & $0(0.0)$ & $28(28.0)$ & $28(14.5)$ & $<0.001$ \\
\hline & Neutral & $10(10.6)$ & $47(47.0)$ & $57(29.4)$ & \\
\hline & Agree/Strongly agree & $84(89.4)$ & $25(25.0)$ & $109(56.1)$ & \\
\hline \multirow[t]{3}{*}{5} & Strongly disagree/Disagree & $0(0.0)$ & $34(34.0)$ & $34(17.5)$ & $<0.001$ \\
\hline & Neutral & $10(10.6)$ & $34(34.0)$ & $44(22.7)$ & \\
\hline & Agree/Strongly agree & $84(89.4)$ & $32(32.0)$ & $116(59.8)$ & \\
\hline \multirow[t]{3}{*}{6} & Strongly disagree/Disagree & $61(64.9)$ & $28(28.0)$ & $89(45.9)$ & $<0.001$ \\
\hline & Neutral & $25(26.6)$ & $36(36.0)$ & $61(31.5)$ & \\
\hline & Agree/Strongly agree & $8(8.5)$ & $36(36.0)$ & $44(22.6)$ & \\
\hline \multirow[t]{3}{*}{7} & Strongly disagree/Disagree & $78(83.0)$ & $27(27.3)$ & $105(54.4)$ & $<0.001$ \\
\hline & Neutral & $13(13.8)$ & $38(38.4)$ & $51(26.4)$ & \\
\hline & Agree/Strongly agree & $3(3.2)$ & $34(34.3)$ & 37 (19.2) & \\
\hline \multirow[t]{3}{*}{8} & Strongly disagree/Disagree & $8(8.5)$ & $28(28.3)$ & $36(18.6)$ & $<0.001$ \\
\hline & Neutral & $42(44.7)$ & $34(34.3)$ & $76(39.4)$ & \\
\hline & Agree/Strongly agree & $44(46.8)$ & $37(37.4)$ & $81(42.0)$ & \\
\hline
\end{tabular}

${ }^{a}$ Key to physician expectation: 1 = Pharmacists should take personal responsibility for resolving any drugrelated problems they discover involving patients; 2 = Pharmacists should be knowledgeable drug-therapy experts; 3 = Pharmacists should assist the physician in designing drug therapy treatment plans for patients; $4=$ Pharmacists should educate patients about the safe and appropriate use of their medication; $5=$ Pharmacists should monitor patients' responses to drug therapy and inform the physician if a patient encounters any drugrelated problem; 6 = Pharmacists should know the specific indication of each drug prescribed, even when drugs have more than one approved or recognized indication; $7=$ Pharmacists should be available to the physician for consultation during patient visits during rounds; 8 = Pharmacists should assist patients in selecting appropriate non-prescription medications

prescription errors, treating minor illness, and suggesting the use of prescription medication to the physician. A similar result was reported among physicians in Qatar and Sudan [13,14]. The results of this study suggest that Iraqi physicians are willing to accept the new patientoriented role of pharmacists.

Approximately half of the participants expected the pharmacist to take responsibility for resolving any drug-related problems, to assist the physician in designing drug therapy treatment plans for patients, and to educate patients about the safe and appropriate use of medicines. However, only a small proportion of the participants agreed or strongly agreed that they expect pharmacists to know the specific indication of each drug prescribed (22 \%) or to be available for consultation when the physicians see patients during rounds (19\%). These low expectations could be explained by the fact that the most participants rarely interact with pharmacists (Table 1), making physicians reluctant to accept a more clinical function for pharmacists. Hence, the pharmacist should be more involved in patient visits to increase physician-pharmacist interaction and hence resolve the issues caused by a lack of interaction; no other healthcare professional can interpret patients' signs, symptoms, and problems regarding medications and their effects as the pharmacist can.

More than $50 \%$ of all Iraqi physicians surveyed reported positively on their experiences with pharmacists. The distribution of responses differed significantly between Erbil physicians and Baghdad physicians $(p<0.05)$. This may indicate that Iraqi hospital pharmacists were ready to cooperate with physicians when asked for more patient-oriented services. Furthermore, physicians do not typically encounter pharmacists conducting such activities in daily practice. The job description of pharmacists within the healthcare system must be well defined and appropriately practiced. A significant correlation exists between a physician's attitude toward the pharmacist's role in healthcare and 
Table 5: Physician experiences with pharmacists $(\mathrm{N}=194)$

\begin{tabular}{|c|c|c|c|c|c|}
\hline $\begin{array}{l}\text { Physician } \\
\text { experience }^{a}\end{array}$ & Response & $\begin{array}{c}\text { Baghdad } \\
\text { N (\%) }\end{array}$ & $\begin{array}{c}\text { Erbil } \\
\mathbf{N}(\%)\end{array}$ & $\begin{array}{c}\text { Total } \\
\text { N (\%) }\end{array}$ & $P$-value \\
\hline \multirow[t]{3}{*}{1} & Strongly disagree/Disagree & $0(0.0)$ & $42(42.0)$ & $42(21.6)$ & $<0.001$ \\
\hline & Neutral & $11(11.7)$ & $34(34.0)$ & $45(23.2)$ & \\
\hline & Agree/Strongly agree & $83(88.3)$ & $24(24.0)$ & $107(55.2)$ & \\
\hline \multirow[t]{3}{*}{2} & Strongly disagree/Disagree & $0(0.0)$ & $37(37.0)$ & 37 (19.1) & $<0.001$ \\
\hline & Neutral & $5(5.3)$ & $40(40.0)$ & $45(23.2)$ & \\
\hline & Agree/Strongly agree & $89(94.7)$ & $23(23.0)$ & $112(57.7)$ & \\
\hline \multirow[t]{3}{*}{3} & Strongly disagree/Disagree & $0(0.0)$ & $34(34.0)$ & 34 (17.5) & $<0.001$ \\
\hline & Neutral & $10(10.6)$ & $41(41.0)$ & $51(26.3)$ & \\
\hline & Agree/Strongly agree & $84(89.4)$ & $25(25.0)$ & $109(56.2)$ & \\
\hline \multirow[t]{3}{*}{4} & Strongly disagree/Disagree & $0(0.0)$ & $34(34.0)$ & $34(17.6)$ & $<0.001$ \\
\hline & Neutral & $27(28.7)$ & $42(42.0)$ & $69(35.6)$ & \\
\hline & Agree/Strongly agree & $67(71.3)$ & $24(24.0)$ & $91(46.8)$ & \\
\hline \multirow[t]{3}{*}{5} & Strongly disagree/Disagree & $0(0.0)$ & $30(30.3)$ & $30(15.6)$ & $<0.001$ \\
\hline & Neutral & $16(17.0)$ & $41(41.4)$ & $557(29.5)$ & \\
\hline & Agree/Strongly agree & $78(83.0)$ & $28(28.3)$ & $106(54.9)$ & \\
\hline \multirow[t]{3}{*}{6} & Strongly disagree/Disagree & $0(0.0)$ & $35(35.0)$ & $35(18.0)$ & $<0.001$ \\
\hline & Neutral & $9(9.6)$ & $33(33.0)$ & $42(21.7)$ & \\
\hline & Agree/Strongly agree & $85(90.4)$ & $32(32.0)$ & $117(60.3)$ & \\
\hline \multirow[t]{3}{*}{7} & Strongly disagree/Disagree & $0(0.0)$ & $34(34.0)$ & $34(17.5)$ & $<0.001$ \\
\hline & Neutral & $8(8.5)$ & $39(39.0)$ & $47(24.2)$ & \\
\hline & Agree/Strongly agree & $85(91.5)$ & $27(27.0)$ & $113(58.3)$ & \\
\hline \multirow[t]{3}{*}{8} & Strongly disagree/Disagree & $6(6.4)$ & $33(33.0)$ & $39(20.1)$ & $<0.001$ \\
\hline & Neutral & $21(22.3)$ & $32(32.0)$ & $53(27.3)$ & \\
\hline & Agree/Strongly agree & $67(71.3)$ & $35(35.0)$ & $102(52.6)$ & \\
\hline
\end{tabular}

${ }^{a}$ Key to physician experience: 1 = Pharmacists are a reliable source of general drug information (e.g., specific facts about drugs); 2 = Pharmacists are a reliable source of clinical drug information (e.g., information regarding the clinical use of a drug in a specific situation.); 3 = Pharmacists routinely counsel the physician's patients on the safe and appropriate use of their medications; 4 = Pharmacists routinely inform the physician if they discover clinical problems with prescriptions; 5 = Pharmacists frequently inform the physician about more cost-effective alternatives to the drugs prescribed; 6- Pharmacists frequently ask the physician to clarify for them the drug therapy objectives the physician has in mind for the patient; 7- Pharmacists frequently let the physician know that a patient has experienced some problem with their medication; 8- Pharmacists appear willing to take personal responsibility for resolving any drug-related problems they discover

his relationship with pharmacists [18]. Therefore, the Iraqi pharmacist should interact positively and frequently with physicians to improve physicians' attitudes toward pharmacists' roles in the healthcare system.

To enhance the interactions between physicians and pharmacists, the pharmacist should be well educated and trained to performed patientoriented functions within the healthcare system. Pharmacy education in Iraq was the first available in the Middle East [19], and the concepts of the clinical pharmacy and pharmaceutical care are included in the college of pharmacy curriculum; nonetheless, a need persists for more extensive clinical training of the pharmacy student to enhance confidence levels and increase interactions with physicians. Some measures have been already taken to pave the way for a better relationship between the physician and the pharmacist. All accredited pharmacy schools currently require students to complete a Doctor of Pharmacy (Pharm D) degree in preparation for more clinically-oriented roles. In addition to its role in pharmacy education, the Ministry of Health plays a vital role in adapting the extended functions of pharmacists to both patients and physicians. This may be achieved not only through promoting the acceptance of the clinical pharmacy and pharmaceutical care concepts in the hospital, but also by creating a set and well-defined job description for the hospital clinical pharmacist.

The Iraqi Ministry of Health initiated a one-year clinical pharmacy training program in 1990 to enable selected fresh pharmacy graduates can enhance their skills and practice of clinical pharmacy. This program, however, is neither a residency nor a specialization [19]. Rasheed et al suggested the adoption of a new training program by medical education institutes to showcase clinical pharmacy as a profession and to prepare board-certified clinical pharmacists as specialists [20]. The Iraqi Board of Clinical Pharmacy (within the Iraqi Board for Medical 
Specialization) program began in 2012 as a specialized degree in clinical pharmacy. The role of the Iraqi pharmacist syndicate is also critical to enhancing the application of pharmacist clinical services through continuous education programs that focus mainly on the pharmacist's patientoriented role. Despite the fact that positive steps have been initiated to improve and promote the clinical services of pharmacists by Iraqi colleges of pharmacy and the Iraqi Ministry of Health, the results of the current study demonstrate that a gap remains between the pharmacist's theoretical knowledge and clinical practice. In other words, the Iraqi pharmacist seems overeducated but underutilized by the healthcare system.

\section{Limitations of the study}

A larger study is recommended to generalize the results and to ensure that the sampled population is representative of the entire physician population. Furthermore, the study only included physicians in government hospitals and excluded those in the private sector.

\section{CONCLUSION}

This study reveals some interesting findings regarding physicians' perceptions, expectations and experiences with pharmacists in Iraqi governmental hospitals. Most importantly, physicians have low regard for the pharmacy profession, and can have negative consequences on their interprofessional relationship and desired collaboration. Strategies looking into overcoming physicians' unacceptance of the pharmacist's role, mainly in patient education and prevention of prescription errors, should be investigated. Physicians in Baghdad reported more positive experience with pharmacists than those in Erbil, a fact explained by the higher rate of interaction between the two professional groups in Baghdad. Thus, holding interprofessional collaborative workshops and conferences in Erbil is necessary. To minimize the gap in collaboration, there should be a collaborative clinical training program for the two professional groups, beginning at both pharmacy and medical colleges, and continued on a longterm basis with the support of the Ministry of Health and the Iraqi pharmacist syndicate. In addition, a well-defined job description of Iraqi hospital pharmacists needs to be developed by the Ministry of Health for the Iraqi health care system.

\section{REFERENCES}

1. American College of Clinical Pharmacy. The definition of clinical pharmacy. Pharmacotherapy 2008; 28(6): 816-817.

2. Hepler CD, Strand LM. Opportunities and responsibilities in pharmaceutical care. Am J Hosp Pharm 1990; 47(3): 533-543.

3. FIP statement of policy on good pharmacy education and practice [Online]. Available: http://www.fip.org/www/uploads/data.

4. Leape LL, Cullen DJ, Clapp MD, Burdick E, Demonaco HJ, Erickson JI \& Bates DW. Pharmacist participation on physician rounds and adverse drug events in the intensive care unit. JAMA 1999; 282: 267-270.

5. Bond CA, Raehl CL \& Franke T. Clinical pharmacist staffing in United States hospitals. Pharmacotherapy 2002; 22: 1489-1499.

6. Bero LA, Mays NB, Barjesteh K \& Bond C. Expanding the roles of outpatient pharmacists: effects on health services utilisation, costs, and patient outcomes. Cochrane Database Syst Rev 2000; CD000336.

7. Cowen $D L$. Changing relationship between pharmacists and physicians. Am J Hosp Pharm 1992; 49(11): 2715-2721.

8. Bradshaw SJ \& Doucette WR. Community pharmacists as patient advocates: physician attitudes. J Am Pharm Assoc, 1998; 38(5): 598-602.

9. Smith WE, Ray MD \& Shannon DM. Physicians' expectations of pharmacists. Am J Health Syst Pharm 2002; 59(1): 50-57.

10. Ranelli PL \& Biss J. Physicians' perceptions of communication with and responsibilities of pharmacists. J Am Pharm Assoc 2000; 40(5): 625630.

11. Sing WS. Pharmacy Practice in Malaysia. Malaysian $J$ Pharm Sci, 2001; 1(1): 3-9.

12. Matowe L, Abahussain EA, Al-Saffar N, Bihzad SM, AlForaih A \& Al-Kandery AA. Physicians' perceptions and expectations of pharmacists' professional duties in government hospitals in Kuwait. Med Princ Pract, 2006; 15(6): 185-189.

13. Zaidan $M$, Singh $R$, Wazaify $M \&$ Tahaineh L. Physicians' perceptions, expectations, and experience with pharmacists at Hamad Medical Corporation in Qatar. $J$ Multidiscip Health 2011; 4: 85-90.

14. Awad A, Matowe $L$ \& Capps P. Medical doctors' perceptions and expectations of the role of hospital pharmacists in Sudan. Pharm World Sci, 2007; 29(5): 557-564.

15. Tahaineh LM, Wazaify $M$, Albsoul-Younes A, Khader $Y$ \& Zaidan M. Perceptions, experiences, and expectations of physicians in hospital settings in Jordan regarding the role of the pharmacist. Res Social Adm Pharm. 2009; 5: 63-70.

16. Higby GJ.. The continuing evolution of American pharmacy practice, 1952-2002. J Am Pharm Assoc 2002; 42: 12-15.

Trop J Pharm Res, February 2015; 14(2): 300 
17. Cruthirds DL, Hughes PJ \& Weaver S. Value of pharmacy services to the healthcare system: an interdisciplinary assessment. Int $\mathrm{J}$ Pharm Pract, 2013; 21(1): 38-45.

18. Muijrers PE, Knottnerus JA, Sijbrandij J, Janknegt $R$ \& Grol RP. Changing relationships: attitudes and opinions of general practitioners and pharmacists regarding the role of the community pharmacist. Pharm World Sci, 2003; 25(5): 235-241.

19. Al-Jumaili AA, Hussain SA \& Sorofman B. Pharmacy in Iraq: history, current status, and future directions. Am J Health Syst Pharm. 2013; 70: 368-372.

20. Rasheed JI \& Abbas HM. Implementation of clinical pharmacy training program in Iraq. Iraqi J Pharm Sci, 2012; 21(1): 1-5. 